\title{
Post-exposure serological responses to malaria parasites in potential blood donors
}

\author{
Daniela Portugal-Calisto ${ }^{1}$, Ana Raquel Ferreira², Marcelo Sousa Silva ${ }^{1,3,4^{*}}$ and Rosa Teodósio ${ }^{1 *}$
}

\begin{abstract}
Background: Cases of transfusion-transmitted malaria have been described around the world and highlighted in some studies. Semi-immune individuals are more likely to transmit malaria as they may be asymptomatic. Some countries allow blood donations only based on epidemiological criteria while others reinforce their criteria with serological tests. However, little is known about the longevity of anti-Plasmodium spp. antibodies and its meaning in blood donation. Therefore, this study aims to assess the longevity of different subclasses of anti-Plasmodium spp. antibodies in individuals with previous stays in endemic areas, as well as to assess how those antibodies are related to personal features and travel characteristics. Based on those results, the suitability of the Portuguese blood donors screening method was addressed, i.e. the method to search for an eventual risk of transfusion-transmitted malaria among the population studied.
\end{abstract}

Results: Statistical associations were found between the presence of total anti-Plasmodium spp. antibodies and some travel characteristics, namely to be born in endemic area versus non endemic and previous episodes of malaria. The intersection between seropositive results and the last year of stay in endemic areas showed a longer longevity of anti-Plasmodium spp. antibodies than previously reported. Those results represented a considerable portion of the individuals having returned from their last stay in endemic areas more than 10 years before enrolment in this study. Considering the study population as potential blood donors, serological results also indicated that if epidemiological criteria alone were applied to screen blood donors, an important percentage of seropositive individuals would be approved for blood donation. Because the nature and meaning of those antibodies in the blood donation context is still not understood, those approved individuals could represent a risk for blood transfusion safety.

Conclusions: The place of birth and past episodes of malaria seem to be related to the serological outcome. Epidemiological criteria to screen potential blood donors are insufficient to guarantee the safety of the blood, if applied alone.

Keywords: Malaria, Plasmodium spp., Anti-Plasmodium spp. antibodies, Longevity, Blood transfusion

\section{Background}

Malaria is an infectious disease with five species of Plasmodium infective to humans. Malaria is endemic in tropical and sub-tropical regions, being the sub-Saharan region the most affected, where Plasmodium falciparum is the most prevalent species [1].

\footnotetext{
*Correspondence: mssilva@ihmt.unl.pt; rosateo@ihmt.unl.pt ${ }^{1}$ Global Health and Tropical Medicine, GHTM, Instituto de Higiene e Medicina Tropical, IHMT, Universidade Nova de Lisboa, UNL, Rua da Junqueira 100, 1349-008 Lisbon, Portugal

Full list of author information is available at the end of the article
}

Since a protective immune response against Plasmodium infection is strain-specific, several infections are required in order to contact with a wide repertoire of Plasmodium antigens and fulfil the compartment of immunologic memory [2]. A protective immunity against the infection is rare or never achieved. However individuals may become semi-immune to the disease, living in balance with the parasite and carrying it in their bloodstream without symptoms [3].

Some studies have suggested that when individuals leave endemic areas for some period of time, semiimmunity may be lost [4]. However, little is known 
about antibody dynamics in the context of malaria and the period of time needed for seroreversion is not well determined. A study of Fowkes et al. which was based on a mathematical model, estimated antibodies half-life of 7.6 years in a population of pregnant women [5]. Faddy et al. studied a population of blood donors and concluded that antibodies anti-Plasmodium spp. may persist in the bloodstream up to 19.6 months after the last exposure [6]. In addition, the majority of the research work published cannot be analysed in the context of the longevity of anti-Plasmodium spp. antibodies: (a) many studies focus on children populations, whose immune system is still in development and thus, it may not be appropriate to extrapolate conclusions to adult populations [7, 8]; (b) some studies were performed in endemic areas where people are constantly at risk of being infected $[8,9]$ and thus, data about the last exposure and antibody longevity may not be accurate; (c) some studies focus mainly on the existence of parasitaemia at the time of blood collection $[10,11]$, and (d) some studies only focus on a small number of parasite proteins that generate a humoral response in vaccine studies [12]. Therefore, to better understand the longevity of malaria antibodies or which features may influence it, a study was conducted in a naturallyexposed adult population that is no longer exposed to the parasite. Since semi-immune individuals may live in balance with the parasite without symptoms, these people are more likely to transmit infection through blood transfusion $[3,13]$.

Transfusion-transmitted malaria has been reported globally, involving children and adults [14-20]. In order to avoid that problem, several governments and other organizations, including the Council of Europe or World Health Organization, created a set of policies and recommendations establishing conditions that shall be applied to potential blood donors [21-23]. In endemic countries, where people are commonly semi-immune, the parasite loads may be undetectable with the available detection techniques. Therefore, transfusion strategies focus on chemoprophylaxis for the donor and recipient, or ensure that the blood collected in areas of high endemicity is not transfused to recipients of low endemicity areas [24]. Despite the efforts, donations frequently end up with the infection of the recipient [20, 25-28]. On the other hand, in nonendemic countries, the strategy to minimize the risk of transmitting malaria through blood transfusion is based on the probability of an individual to transmit the parasite at the moment of blood donation. Therefore, some countries only apply selective epidemiological questionnaires (e.g. Canada, USA) [29-31], while others reinforce their selection measures with immunological tests and/or molecular techniques (e.g. Australia, France, England, Italy, Spain and Portugal [21, 32-36]. The Portuguese Institute for Blood and Transplantation bases its procedures on a Portuguese statement that regulates blood donations for individuals with stays in malaria-endemic areas, who wish to donate blood [21-23, 37]; Table 1 summarizes the Portuguese criteria for donors approval.

The historical and cultural proximity between Portugal and some endemic countries, such as Angola, GuineaBissau, São Tomé and Príncipe, Mozambique, and Brazil, makes Portugal at risk of receiving semi-immune people that later may donate blood [38]. Besides, there are no estimates about the prevalence of individuals with anti-Plasmodium spp. antibodies in Portugal. Thus, the present work aims to better understand the dynamics of anti-Plasmodium spp. antibodies in a population of adults, naturally-exposed to Plasmodium spp. at some moment of their lives. Specifically, this study aims to determine the longevity of anti-Plasmodium spp. antibodies; how that longevity may be related to demographic characteristics and travel features; and, according to that, a question about the suitability of the screening method of blood donors was raised, regarding the substantial need of blood units versus the potential risk of transmitting malaria.

\section{Table 1 Criteria for donor blood screening, according to the Portuguese Institute for Blood and Transplantation}

\begin{tabular}{lc}
\hline Risk category & Guidelines \\
\hline $\begin{array}{l}\text { Individuals who lived the first } 5 \text { years of life in endemic areas } \\
\text { Previous episodes of malaria }\end{array}$ & $\begin{array}{c}\text { Approved } 3 \text { years after the last stay in endemic areas, since asymptomatic } \\
\text { or approved } 4 \text { months after return if serological or molecular tests are } \\
\text { negative } \\
\text { Asymptomatic visitors (stays }<6 \text { months) }\end{array}$ \\
$\begin{array}{l}\text { Febrile episodes undiagnosed during or } 6 \text { months after a travel to } 3 \text { years after cessation of last symptoms/treatment and only if } \\
\text { endemic areas }\end{array}$ & $\begin{array}{c}\text { Approved } 1 \text { year after returning of endemic areas or approved if serological } \\
\text { or molecular tests are negative } \\
\text { Approved } 3 \text { years after returning from endemic areas and cessation of } \\
\text { symptoms or approved } 4 \text { months after return if serological or molecular } \\
\text { tests are negative }\end{array}$
\end{tabular}




\section{Methods}

\section{Study population}

The population studied included 505 individuals that fulfil the following criteria: (1) age between 18 and 65 years old; (2) have stayed in endemic areas of malaria, independently of having a history of malaria episodes, length of stay or reason for travelling.

All individuals that attended different phlebotomy services in Lisbon, between September 2010 and January 2011, and between March and July 2014, and fulfilled the criteria above were invited to participate. Individuals with laboratory diagnostic of malaria at the time of blood collection were excluded and directed to medical experts for follow-up. Any other pathology that people might have had did not interfere with the serologic test used. People included were considered as potential blood donors. An informed consent and a signed permission to give $3 \mathrm{ml}$ of blood for malaria studies were applied to all subjects at the time of enrolment. A questionnaire assessing the risk of exposure was also given to all subjects included. This study was approved by the Ethical Council of the Institute of Hygiene and Tropical Medicine of Lisbon, Portugal.

\section{Sample collection}

Total blood was collected by venepuncture into $3 \mathrm{ml}$ ethylenediamine-tetraacetate (EDTA) tubes. $15 \mu \mathrm{l}$ of total blood was absorbed in filter paper discs of $11 \mathrm{~mm}$ (Whatman, USA), allowed to dry at room temperature for $24 \mathrm{~h}$ and stored at $4{ }^{\circ} \mathrm{C}$. The remaining sample was centrifuged at $4000 \mathrm{~g}$ for $15 \mathrm{~min}$, and plasma was stored at $-20^{\circ} \mathrm{C}$.

\section{Serological measurement of anti-Plasmodium spp. antibodies}

Total anti-Plasmodium spp. antibodies were searched in 505 samples, by a commercial immunoenzymatic assay named EIA Malaria Kit Test (Bio-Rad, USA), following the manufacturer's instructions. This test is used in the Portuguese Institute for Blood and Transplantation to screen potential blood donors regarding the risk of transmitting malaria by blood transfusion.

The immunoassay uses four recombinant proteins immobilized on a solid phase where anti-Plasmodium spp. antibodies will bind if present in the serum/plasma sample. Three of the four recombinant proteins are specific to P. falciparum, with cross-reactivity for Plasmodium malariae and Plasmodium ovale, and the fourth recombinant protein is specific for Plasmodium vivax. These proteins can detect total immunoglobulins (Ig) from class G, M and A, although not separately.

The threshold was obtained by calculating the quotient of the optical density (OD; measured for each sample) and the cut-off, which is the mean of the negative controls for each plate plus a ponderation of 0.1 (as indicated by the manufacturer). This method allowed reproducible and comparable results between assays. Thus, samples with an OD/cut-off lower than 0.9 were considered negative while samples above 1.1 were considered positive. Samples with values $10 \%$ upper or $10 \%$ down 1.0 (ranging from 0.91 to 1.09 ) were repeated and, when the value persisted, were considered inconclusive.

\section{DNA extraction and amplification}

Polimerase chain reaction (PCR) was performed to verify if seropositive results were due to acute infections. Plasmodial genomic DNA was extracted from dried bloodspots of the seropositive samples and negative controls, using Chelex-100 (Bio-Rad, USA), following a protocol adapted from Kain and Lanar's work [39]. Approximately $1 / 4$ of a $6 \mathrm{~mm}$ diameter filter paper with blood absorbed was excised, corresponding to approximately $5 \mu \mathrm{l}$ of sample. Each excised filter paper was added to a $1.5 \mathrm{ml}$ microcentrifuge tube with $300 \mu \mathrm{l} 10 \%(\mathrm{w} / \mathrm{v})$ Chelex-100 and vortexed for $15 \mathrm{~s}$, followed by a short spin. Tubes were placed in a heating block at $95{ }^{\circ} \mathrm{C}$ for $20 \mathrm{~min}$. Samples were vortex for $15 \mathrm{~s}$ and a new short spin was made. The supernatant was transferred into a new $1.5 \mathrm{ml} \mathrm{micro-}$ centrifuge tube and stored at $-20{ }^{\circ} \mathrm{C}$ until required for DNA amplification.

PCR reactions were performed for all subjects that were positive in the ELISA technique. DNA of $P$. falciparum, $P$. vivax, $P$. malariae and $P$. ovale was amplified by nested-PCR, using primers that recognize the small subunit (18S) ribosomal RNA gene, designed by Snounou et al. [40]. For amplification, the protocol was adapted from the manufacturer's instructions of MyTaq BloodPCR Kit (Bioline, UK). Thus, for each PCR reaction were used $12.5 \mu \mathrm{l}$ of MyTaq Blood-PCR Mix, 2x; $1 \mu \mathrm{l}$ of $10 \mu \mathrm{M}$ forward primer; $1 \mu \mathrm{l}$ of $10 \mu \mathrm{M}$ reverse primer; $1 \mu \mathrm{l}$ of DNA extracted and DEPC-treated water (DNAses and RNAses free) (Bioline, UK) up to $25 \mu \mathrm{l}$.

Amplification conditions were: (a) initial denaturation at $94{ }^{\circ} \mathrm{C}$ for 2:00 min; (b) denaturation at $94{ }^{\circ} \mathrm{C}$ for 0:30 min; (c) annealing at $55^{\circ} \mathrm{C}$ for $1: 30 \mathrm{~min}$; (d) extension at $72{ }^{\circ} \mathrm{C}$ for 2:00 min; repeat step (b) to (d) for 40 cycles; (e) final extension at $72{ }^{\circ} \mathrm{C}$ for 10:00 min. DNA extraction was accompanied by a negative control (a piece of blank filter paper) and additionally, every PCR run included a negative control to which no template was added.

\section{Questionnaire}

Subjects included were asked to fill in a questionnaire about personal characteristics such as age, country of birth and years of continuous residence in that country after birth; and travel features namely length of stay in endemic areas of malaria; length of time since the last 
stay and previous history of malaria. Since epidemiological studies using questionnaires are susceptible to errors due to recalls, the last stay in endemic areas was considered to be the most reliable moment from which there was no more risk of exposure to Plasmodium sp. and thus, the last possibility of having a new infection that may justify the antibodies detected at the time of this study. That variable is preferred over the last episode of malaria for several reasons: (1) a person may remain at risk of infection after the disease, every time he/she is in an endemic area; (2) a person may harbour parasites asymptomatically and (3) because the last episode of malaria adds more uncertainty concerning to when it occurred.

The "length of stay" is the duration of the last travel. A short stay was defined as a period of time spent in endemic areas of less than 6 months; and a long stay was considered a period of time of 6 or more months continuously spent in endemic areas. The variable "length of time since the last stay" refers to the time passed since the moment that a person leaves endemic areas until the moment of enrolment in this study. It was categorized according to the criteria for blood donation in Portugal (Table 1).

A pre-test of the questionnaire was made. Since technical questions were not asked, a self-administered questionnaire was applied. The questionnaire included closed, single-choice questions and open questions.

\section{Statistical analysis}

Quantitative variables were described using mean and standard deviation (SD) or median. Data were analysed using descriptive statistic and hypothesis tests such as Chi Square test of independence, and Mann-Whitney U test for independent samples [41, 42]. A statistical significance level of $5 \%$ was used to search for statistical associations or differences between the variables studied. Only the variables statistically significant $(\mathrm{p}<0.05)$ in bivariate analysis were maintained in the second model. Multivariate analysis was performed in two steps: a first one using a univariate logistic regression and a second step using multiple logistic regression, based on forward likelihood ratio method. The quality of the adjustment of the model was assessed using Hosmer and Lemeshow Test. The hypothesis $\mathrm{H}_{0}$ was excluded when $\mathrm{p}<\alpha(\alpha=0.05)$. The adjustment of the logistic regression model was also performed using a statistical significance level of 5\%. Statistical analyses were performed with IBM SPSS Statistics version 20.0 software (IBM SPSS Statistics for Windows, Version 20.0. Armonk, NY: IBM Corp.).

\section{Results}

\section{Characteristics of the studied population}

This study included 505 individuals with previous stays in endemic areas of malaria, of which 336/505 were men (66.5\%) and 169/505 were women (33.5\%). The mean age was 41.34 years (95\% confidence interval: 40.27-42.41), $\mathrm{SD}=12.229$, ranging from 18 to 65 years old. The median age was 40 years old. The most represented nationalities were Portugal (73.3\%), followed by Angola (13.1\%) and Mozambique (5.8\%). Overall, approximately $75.8 \%$ of the individuals were born in a nonendemic malaria country. Table 2 summarizes the frequency of the variables studied.

Although 120 respondents were born in endemic areas of malaria, only 75 individuals lived the first 5 years of life in the endemic areas where they were born. Regarding previous episodes of the disease, "no previous history of malaria" was the answer for the majority of the respondents (Table 2). From the individuals that answered "having history of malaria" (165/505), only 38.6\% (63/163) of individuals were born in endemic areas of malaria against to $61.3 \%(100 / 163)$ not born in endemic areas (Additional file 1).

Regarding the amount of travels to endemic areas of malaria, there are more people that travelled only once, contrarily to people who travelled more than 10 times to endemic areas, who accounts for the minor subpopulation. For the majority of the respondents, the length of stay in endemic areas was less than 6 months. Relatively to the length of time since the last stay in endemic areas, there are two subpopulations that stands out: one returning 4 months before their enrolment and another subpopulation that returned more than three years before the study (Table 2), of which 63\% (113/179) had their last stay to endemic areas more than 10 years before their enrolment (Additional file 2).

\section{Serological profile and DNA detection}

The prevalence and level of total anti-Plasmodium spp. antibodies were determined with EIA Malaria Kit Test (Bio-Rad, USA). According to the serological results, 67 individuals (13.3\% of the total) were seropositive against Plasmodium spp. and 435 individuals (86.1\%) were seronegative against the parasite [three results $(0.6 \%)$ were inconclusive]. The distribution of the levels of total anti-Plasmodium spp. antibodies among the population studied $(\mathrm{n}=505)$ are presented in Fig. 1a.

In order to understand how total anti-Plasmodium spp. antibodies are present in the population studied, we analysed the distribution of the levels of those antibodies 


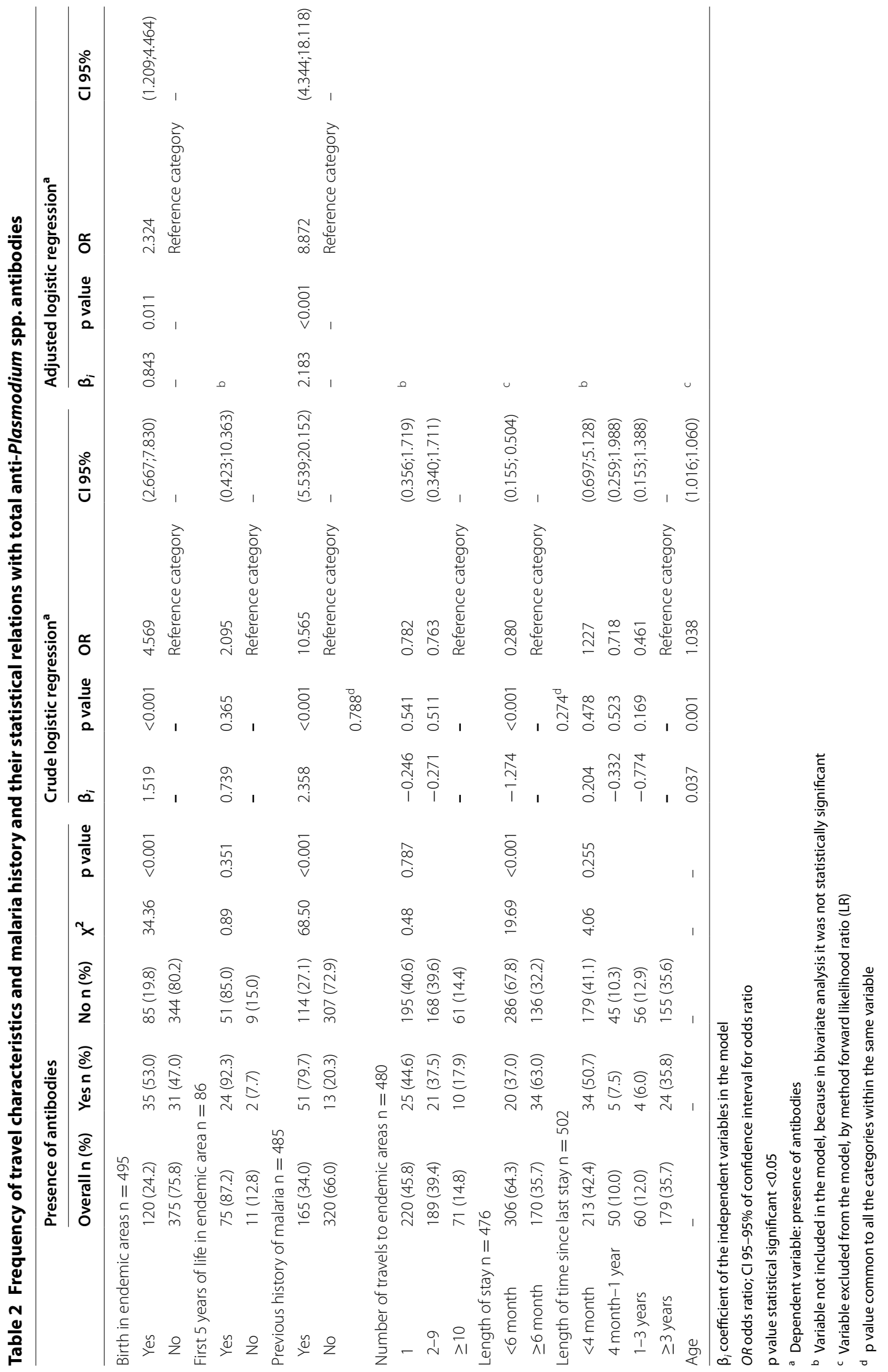



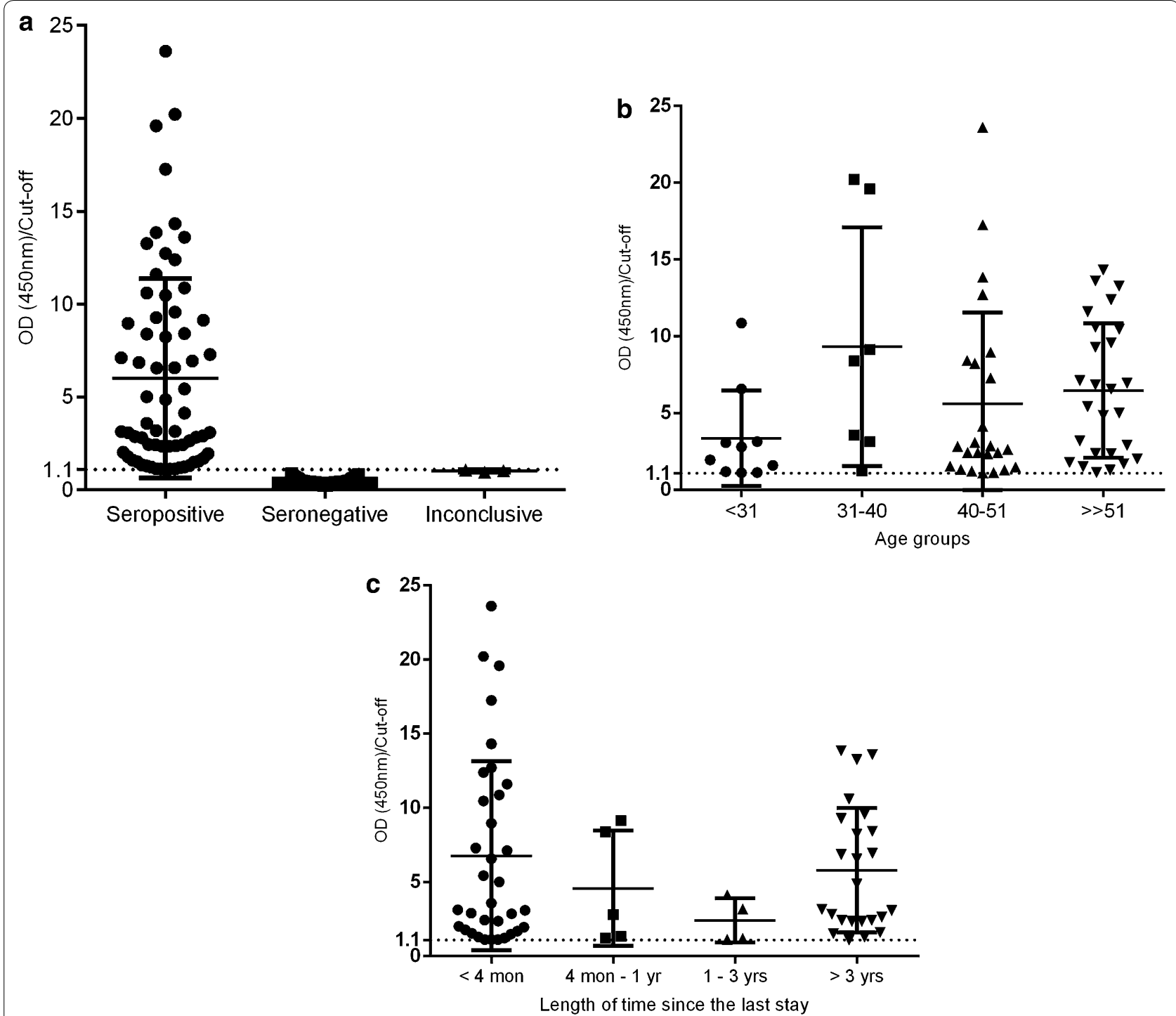

Fig. 1 Distribution of levels of total anti-Plasmodium spp. antibodies, according to $\mathbf{a}$ ELISA results: seropositive $(n=67)$; seronegative $(n=435)$ and inconclusive $(n=3)$; $\mathbf{b}$ distribution of levels of total anti-Plasmodium spp. antibodies of the seropositive group, according to age groups: $<31$ years old (10/67; 14.9\%); 31-40 years old (7/67; 10.4\%); 40-51 years old (24/67; 35.8\%); $\geq 51$ years old $(26 / 67 ; 38.8 \%)$; c Distribution of levels of total antiPlasmodium spp. antibodies of the seropositive group, according to the length of time since the last stay in endemic areas of malaria: $<4$ months (34/67; 50.7\%); 4 months -1 year $(5 / 67 ; 7.5 \%) ; 1-3$ years $(4 / 67 ; 6 \%) ; \geq 3$ years $(24 / 67 ; 35.8 \%)$

according to age group and the length of time since the last stay in endemic areas of malaria (Fig. 1b, c, respectively). The variable "age" was categorized according to percentiles $\mathrm{P}_{25}=31$ years old; $\mathrm{P}_{50}=40$ years old and $\mathrm{P}_{75}=51$ years old. The percentage of seropositivity per percentile is presented in Fig. 2. The groups with more percentage of seropositive individuals correspond to the percentiles of $\mathrm{P}_{50}$ and $\mathrm{P}_{75}$, being also the subgroups with a higher value of OD/cut-off. Regarding the length of time since the last stay in endemic area, there are more seropositive individuals returned 4 months before their participation in the study and returned 3 or more years before their participation (Fig. 1c).

In order to distinguish between acute infections from old infections in seropositive subjects, and to help to assure that the seropositivity detected is not due to circulating parasites, PCR reactions were made. Samples with Plasmodium DNA were excluded and thus, all subjects included were negative in PCR at the time of blood collection. 


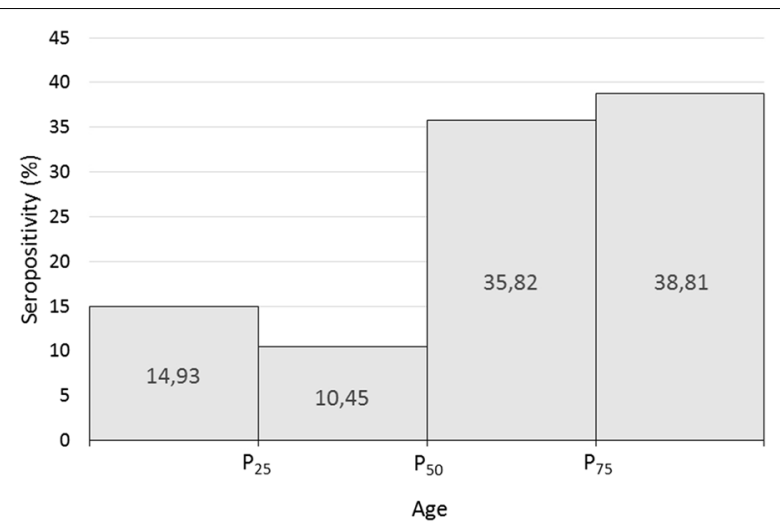

Fig. 2 Percentage of seropositive individuals according to the presence of total antibodies anti-Plasmodium spp. in each percentile. Variable "Age" categorized according to $\mathrm{P}_{25}, \mathrm{P}_{50}$ and $\mathrm{P}_{75}$, resulting in four age groups: $<31$ years old $(10 / 67 ; 14.9 \%) ; 31-40$ years old $(7 / 67$; $10.4 \%) ; 40-51$ years old $(24 / 67 ; 35.8 \%) ; \geq 51$ years old $(26 / 67 ; 38.8 \%)$

\section{Statistical relation between the variables studied and total anti-Plasmodium spp. antibodies}

Individual and travel features that could justify the longevity of total anti-Plasmodium spp. antibodies were searched and statistically analysed. In the bivariate statistical analysis, the presence of total antibodies anti-Plasmodium spp. is statistically associated with the length of stay in endemic areas $\left(\mathrm{N}=476, \mathrm{X}^{2}=19.69, \mathrm{p}<0.001\right)$ (Table 2). Notwithstanding, the level of total antibodies seems to be higher in individuals that stayed in endemic areas for periods of time of 6 or more months (MannWhitney $U=29.90, \mathrm{p}<0.05$ ) (Additional file 3).

Having been born in endemic areas may be an important feature to influence the presence of anti-Plasmodium spp. antibodies $\left(\mathrm{N}=495, \mathrm{X}^{2}=34.36, \mathrm{p}<0.001\right)$, such as a previous history of malaria $\left(\mathrm{N}=485, \mathrm{X}^{2}=68.50\right.$, $\mathrm{p}<0.001$ ) (Table 2).

The logistic regression model excluded some of the statistical significant variables calculated in the bivariate analysis, indicating that only the variables "Birth in endemic areas" and "Previous history of malaria" were statistically significant, with $p=0.011$ and $p<0.001$, respectively (Table 2). The odds ratio of having been "Born in endemic areas" was $2.324\left(\mathrm{CI}_{95 \%} 1209 ; 4464\right)$ comparatively to 'Not born in endemic areas', which means that having been born in an endemic area increases in $132.4 \%(2.324-1 \times 100)$ the possibility of having antibodies. Notwithstanding, the odds ratio of having a previous history of malaria was $8.872\left(\mathrm{CI}_{95 \%}\right.$ $4344 ; 18,118)$ comparatively to not have a previous history of malaria. In this case, a previous history of malaria increases in $878.2 \%$ the probability of an individual be seropositive (Table 2). The Hosmer and Lemeshow test, with a $p$ value of 0.027 , led to the rejection of the null hypothesis and to the conclusion that the model does not fit well the data (Additional file 4).

Regarding to the last stay in endemic areas of malaria, and comparing the year of the last exposure with the level of anti-Plasmodium spp. antibodies, two seropositive groups stand out: individuals returned in the last 2 years and another important population returned from endemic areas more than 10 years before their enrolment. The oldest exposures among seropositive individuals occurred 43 years before their participation in the study (Fig. 3).

\section{Implication of anti-Plasmodium spp. antibodies in blood donation}

Considering that all individuals were negative in PCR and thus, considered as potential blood donors, the percentage of donors approved for blood donation was assessed, according to the Portuguese criteria for blood donors screening. Table 4 shows that if epidemiological criteria were applied alone to screen blood donors, there would be a risk of seropositive individuals be approved for blood donation. On the other hand, when laboratory criteria were applied in combination with the epidemiological criteria, the percentage of individuals approved was lower but it did not carry risk for blood donation.

\section{Discussion}

Malaria is a serious condition that still affects many people worldwide, being a major cause of transfusion-transmitted diseases [43], and Portugal remains an important destination for people travelling from endemic areas [38, $44,45]$. Asymptomatic people represent an important risk to malaria transmitted through blood transfusion $[46,47]$. The existence of anti-Plasmodium spp. antibodies in a blood unit may represent a risk of malaria transmission, since it is not clear what their presence means in the context of blood transfusion. As a result,

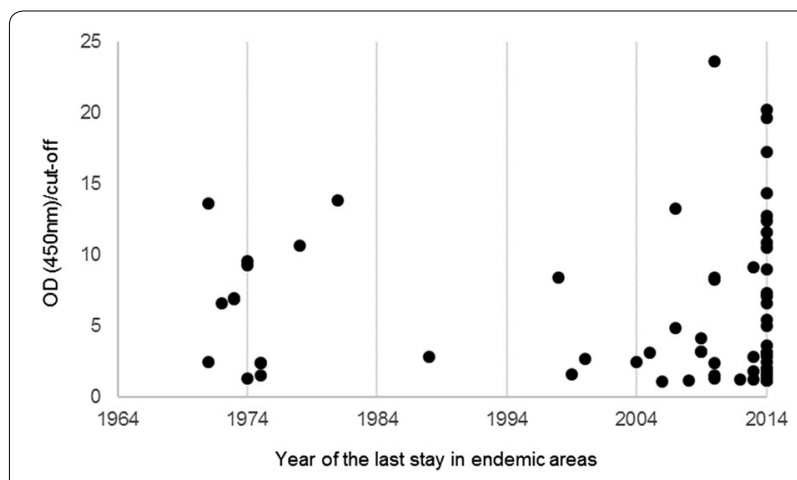

Fig. 3 Distribution of antibody levels among the seropositive group, according to the year of their last stay in endemic areas of malaria 
all seropositive individuals for malaria are excluded from blood donations.

The longevity of those antibodies is also not well determined, with several studies indicating different half-life of antibodies anti-Plasmodium spp. [5, 6]. Therefore, the effect of malaria exposures in the blood donation context was analysed, treating the subjects included as potential blood donors and thus, applying the Portuguese criteria for donor eligibility. Characteristics that could justify the longevity of the antibodies detected were also searched.

A group of 505 people, ranging from 18 to 65 years old, with previous stays in endemic areas of malaria were included. The majority of the individuals were born in Portugal (a nonendemic area), and thus its immune system was not stimulated against Plasmodium antigens during childhood. Negative results from PCR indicate that none of the serological reactivity detected were due to acute infections at the time of enrolment. Overall, $13.3 \%$ of the individuals were seropositive for antibodies anti-Plasmodium spp. Statistical analysis were performed to search for associations between the presence of total anti-Plasmodium spp. antibodies and some personal and travels characteristics (age; country of birth; number of travels to endemic areas; the length of stay in endemic areas and the length of time since the last stay). Results are summarized in Tables 2 and 3.

The effect of age is not completely understood. Although some studies suggest that a protective immune response is acquired and developed early in life, others indicate that a more mature immune system develops a specific immune response more efficiently [48-50]. The results obtained in the present study suggest that the presence of total anti-Plasmodium spp. antibodies is not related to the age of subjects, being a confounding variable of the studied population. However, analysing the percentiles of the variable "age" it is possible to notice that there are more seropositive subjects in the two older percentiles (Fig. 2). The only study founded enrolling an adult population showed a high prevalence of antibodies against $P$. vivax between the ages of $25-50$ years [51]. The results reported in the present study indicate that there are more percentage of individuals with total antibodies against Plasmodium spp. from 40 to 65 years old than among younger individuals, aged from 18 to 40 years (Fig. 2).
To be born in endemic areas seems to be an important feature that may justify the presence of anti-Plasmodium spp. antibodies ( $\left.\mathrm{OR}=2.324\left[\mathrm{CI}_{95 \%} 1209 ; 4464\right]\right)$. Although it has been described that children under 5 years old are one of the most vulnerable groups to malaria infections [52], the present report suggests that living the first 5 years of life in those areas does not seem to be related to the persistence of total anti-Plasmodium spp. antibodies until adulthood. Mackinstosh and colleagues analysed the blood of 272 children under 10 years old and indicated the presence of anti-Plasmodium falciparum antibodies only in parasitized children, suggesting that those antibodies may be short-lived [53]. To be true that age per se is not a factor that stimulates antibodies that can persist for long periods of time, these results may raise a question about the applicability of some criteria in blood donations.

According to the statistical results obtained in this study, the presence of total antibodies is related to a previous history of malaria $\left(\mathrm{N}=485, \mathrm{X}^{2}=68.50, \mathrm{p}<0.001\right)$, $\left(\mathrm{OR}=8.872\left[\mathrm{CI}_{95 \%} 4344 ; 18,118\right]\right)$, although it does not take into account the moment when it occurred. Those results are consonant with a study of Nguyen including blood donors in the USA, in which the authors analysed the risk of transfusion-transmitted malaria between a group of deferred donors and a group of accepted blood donors [54]. That study suggests that there is a significant risk of transmitting malaria through blood transfusion when people with past episodes of malaria are accepted for donation (without serologic testing) [54]. Although the presence of total anti-Plasmodium spp. antibodies seemed to be also dependent of the length of stay in endemic areas $\left(\mathrm{N}=476, \mathrm{X}^{2}=19.69, \mathrm{p}<0.001\right)$ according to bivariate analysis, the logistic regression model indicated that this is another confounding variable. Regarding other variables studied, as the number of travels to endemic areas and the time passed since the last stay in endemic areas (as well as the first 5 years of life in endemic areas, already mentioned above), statistical analysis indicate that serological results are independent of those variables, showing no differences statistically significant.

The logistic regression model excluded some of the variables that were statistical significant on the bivariate analysis, indicating that only the variables "birth in

Table 3 Statistical relation between variable "age" and serological results

\begin{tabular}{llllll}
\hline Variables & & $\begin{array}{l}\text { Median age } \\
\text { (years) }\end{array}$ & $\begin{array}{l}\text { Mean age } \\
\text { (years) }\end{array}$ & $\begin{array}{l}\text { Mann-Whitney } U \\
\text { Test }\end{array}$ & Mean rank \\
\hline Age $(n=502)$ & Group of seropositive $(n=67)$ & 46 & $46.13 \pm 1.46$ & 10.69 & 309.40 \\
& Group of seronegative $(n=435)$ & 39 & $40.59 \pm 0.58$ & & $<0.001$ \\
\hline
\end{tabular}


endemic areas" and "previous history of malaria" are statistically significant. Therefore, the variables "length of stay" and "age" are possible confounding variables. Although model's coefficients were statistically significant, Hosmer and Lemeshow test indicated that there was no good quality of model's adjustment, which can be explained by the existence of other features not included in this study that could better explain the presence and longevity of total anti-Plasmodium spp. antibodies.

Although statistical analysis does not give a significant meaning when serological results are analysed regarding the length of time since the last stay (Table 2), the analyses of Fig. 3 shows two important populations that shall be highlighted: one corresponds to individuals who returned from endemic areas within 2 years before the study, and another population showing serological reactivity $40-50$ years after the last stay in endemic areas. The two oldest exposures correspond to two people with stays in African countries: one Portuguese man that travelled to Guinea-Bissau for military duties, reported previous episodes of malaria and returned in 1971, with no more stays in endemic areas since. The second person, also a man, was born in Mozambique and lived there for 4 years, between 1967 and 1971, returning 43 years before the study execution, not having history of malaria episodes. The literature is ambiguous about the longevity of anti-Plasmodium spp. antibodies, but it can be found that the humoral immune response against Plasmodium spp. may be transient, remaining up to 3-5 years without re-exposures [55]. A study of Fowkes et al. including a population of pregnant women in northwestern Thailand, estimated a half-life of 7.6 years for antibodies against PfAMA1 of $P$. falciparum in infected women, although for uninfected participants the longest persistence time calculated was only 3.1 years for MSP2 of $P$. falciparum [5]. Faddy et al. investigated the longevity of antibodies in a population of blood donors in a nonendemic area and indicated a median seroreversion time of 19.6 months. Also, the authors estimated that $20 \%$ of people with stays in endemic area of less than 6 months would serorevert 3 years after the initial reactive result, and $2 \%$ of the people with stays in endemic areas of more than six months would test seronegative in 5 years [6]. A study of Druilhe et al. reported the presence of antibodies against $P$. falciparum sporozoites in African adults up to 11 years after the last exposure [56]. Therefore, the persistence of antibodies detected in the present report is significantly longer than previously described $[5,6,56]$.

The implication of the antibodies detected for blood donation was determined only for two of the four Portuguese blood donation criteria due to its inapplicability: the condition "Individuals with previous episodes of malaria" uses epidemiological and laboratory criteria that are dependent, not allowing a person to donate blood if one of the criteria is not verified, and thus our analyse could not be done. The condition "Individuals with febrile episodes undiagnosed during or 6 months after a travel for endemic areas" cannot be analysed in this study, since the database did not include symptomatic individuals.

As shown in Table 4, epidemiological criteria (which only rely in the length of time since the last stay in endemic areas) approve a higher percentage of potential blood donors than laboratory criteria. However, it carries a risk for blood safety since epidemiological criteria alone would allow the donation of blood from individuals that are seropositive for malaria. Moreover, laboratory criteria are more selective and the percentage of approval is significantly lower. It seems that epidemiological criteria used alone are insufficient to guarantee the blood safety and that laboratory criteria are more reliable once all the individuals approved would be seronegative, and thus the uncertainty about blood safety decreases.

Despite all efforts made to obtain accurate answers from epidemiological questionnaires, these kind of

\section{Table 4 Percentage of donors approved according to the Portuguese criteria for blood screening and serologic results}

\begin{tabular}{|c|c|c|c|c|}
\hline Condition & & Criteria for approval & Donors approval \% & \\
\hline \multirow[t]{2}{*}{$\begin{array}{l}\text { Individuals who lived the first } \\
5 \text { years of life in endemic areas } \\
(n=85)\end{array}$} & Epidemiological criterion & 3 year after return $(n=45)$ & $52.9(45 / 85)$ & $\begin{array}{l}\text { Of which } 28.9 \%(13 / 45) \text { that } \\
\text { would be approved were } \\
\text { seropositive }\end{array}$ \\
\hline & Laboratory criterion & $\begin{array}{l}\text { If returned between } 4 \text { month } \\
\text { and } 3 \text { year and seronegative } \\
(n=14)\end{array}$ & $16.5(14 / 85)$ & $\begin{array}{l}\text { (All approved would be } \\
\text { seronegative) }\end{array}$ \\
\hline \multirow[t]{2}{*}{$\begin{array}{l}\text { Asymptomatic travellers (length } \\
\text { of stay }<6 \text { months) from } \\
\text { endemic areas }(n=308)\end{array}$} & Epidemiological criterion & 1 year after return $(n=147)$ & $47.7(147 / 308)$ & $\begin{array}{l}\text { Of which } 5.4 \%(8 / 147) \text { that } \\
\text { would be approved were } \\
\text { seropositive }\end{array}$ \\
\hline & Laboratory criterion & $\begin{array}{l}\text { If returned between } 4 \text { month } \\
\text { and } 1 \text { year with serological test } \\
\text { nonreactive }(n=31)\end{array}$ & $10.1(31 / 308)$ & $\begin{array}{l}\text { (All approved would be } \\
\text { seronegative) }\end{array}$ \\
\hline
\end{tabular}


studies are susceptible to recall bias, which is important to consider when analysing the results.

Serological assays used as screening methods do not necessarily indicate that a person is infected at the moment of the donation, but it constitutes an important indicator to measure the risk of transmitting this infectious disease. In the USA, where the screening of blood donors relies only in epidemiological questionnaires and periods of suspension, it was described a case of transfusion-transmitted malaria caused by $P$. malariae 44 years after exposure in an endemic area of malaria [57]. The present study intends to alert for similar cases, since it was detected anti-Plasmodium spp. antibodies many years after exposure and the risk for blood transfusion is not known yet. Thus, measures of eligibility of blood donors should be reinforced. Complementary measures to ensure the safety of the blood may include policies that demand blood screening in areas where those policies do not exist yet, and that blood screening at a laboratory level becomes a regular procedure in every blood donation. Other studies have suggested that the screening of blood donors should include the antigen detection with monoclonal antibodies or the detection of its nucleic acids, in order to reinforce the performance of serologic tests and improve the screening methods and, consequently, improve blood safety $[58,59]$.

New studies should be performed to deeply investigate molecular characteristics and immunological effects of those antibodies detected decades after exposure. Other subjects or travel characteristics should be considered to contribute to the longevity of anti-Plasmodium spp. antibodies. The implication of those antibodies on the criteria of donors eligibility (including the two other requirements for blood donation not contemplated in the present work) should also be assessed in broader and representative populations.

\section{Conclusions}

In the present study, an important percentage of individuals returned from endemic areas more than 10 years before their enrolment was detected with total anti-Plasmodium spp. antibodies circulating in their bloodstream.

Some factors that may influence the longevity of total anti-Plasmodium spp. antibodies over time were identified: (a) had been born in endemic areas and (b) previous history of malaria. On the other hand, living in endemic areas during childhood does not seem to be related to the longevity of total anti-Plasmodium spp. antibodies, as well as the number of travels to endemic areas or the length of time spent in endemic areas, for the population studied. Although the length of time since the last stay in endemic areas was not statistically significant, the presence of total anti-Plasmodium spp. antibodies in the bloodstream of individuals many years after exposure, with no history of malaria in the meantime, is important to highlight.

In the blood donation context, epidemiological questionnaires should be reinforced with serological tests to guarantee the safety and quality of the blood donated. New studies should be performed to understand the biological nature of those long-lived immunoglobulins, their specific role in the immunity of malaria and their implication in blood transfusion.

\section{Additional files}

Additional file 1. Frequency of individuals born in endemic versus nonendemic area of malaria regarding previous history of malaria.

Additional file 2. Frequency of people returned from endemic areas 10 or more years before their enrolment in the study, among the subgroup of subjects returned 3 and more years before enrolment.

Additional file 3. Frequency and levels of total anti-Plasmodium spp. antibodies comparing the two subgroups of subjects: with a length of stay of less than 6 months and a length of stay of 6 or more months in endemic areas of malaria. The presentation was adapted from the result obtained in Mann-Whitney $U$ test.

Additional file 4. Contingency table for Hosmer and Lemeshow Test.

\section{Authors' contributions}

DPC: helped design the study; obtained epidemiological data and samples; performed serological and molecular studies, as well as statistical analysis; wrote and revised the manuscript. ARF: helped design the study; organized sample collection; obtained epidemiological data and samples and performed serological analyses. MSS: conceived and designed the study; performed serological and molecular studies and revised the manuscript. RT: conceived and designed the study; performed and revised statistical analysis and revised the manuscript. All authors read and approved the final manuscript.

\section{Author details}

${ }^{1}$ Global Health and Tropical Medicine, GHTM, Instituto de Higiene e Medicina Tropical, IHMT, Universidade Nova de Lisboa, UNL, Rua da Junqueira 100, 1349-008 Lisbon, Portugal. ${ }^{2}$ Instituto Português do Sangue e da Transplantação, Parque de Saúde de Lisboa, Av. do Brasil, 53-Pav. 17, 1749-005 Lisbon, Portugal. ${ }^{3}$ Department of Clinical and Toxicological Analysis, Faculty of Pharmacy, Universidade Federal do Rio Grande do Norte, Campus Universitário Lagoa Nova, Natal 59078-970, Brazil. ${ }^{4}$ Programa de Pós-graduação em Bioquímica, Universidade Federal do Rio Grande do Norte, Campus Universitário Lagoa Nova, Natal 59078-970, Brazil.

\section{Acknowledgements}

Thanks to all the associations and laboratories that help us to do the recruitment of individuals. Thanks to Associação dos Deficientes das Forças Armadas, inclusively Mr. Francisco Janeiro; to Lar Militar da Cruz Vermelha Portuguesa (in Lisbon), particularly to the nurses Teresa Mendonça and Artur Batista and Dr. Natércia; to the laboratory Medicil; to Laboratório de Análises Clínicas Dr. Francisco Faria, specifically Dr. Sónia Faria and Dr. Magda and to the laboratory Topcare, namely to Dr. Maria Leonor Barreira. A special acknowledgement to Eleonora Paixão, from Alentejo Regional Administration of Health, for all the support with statistical analyses.

\section{Competing interests}

The authors declare that they have no competing interests.

Consent for publication

All authors have approved their participation in the publication of this manuscript. 


\section{Ethics approval and consent to participate}

A questionnaire was applied to each individual who accepted to participate in this study and had signed the inform consent, to collect information about their previous stays in endemic areas of malaria and previous malaria episodes. This study was approved by the Ethical Council of Instituto de Higiene e Medicina Tropical of Lisbon, Portugal.

\section{Funding}

The authors want to thank to GHTM for financial support (FCT for funds to GHTM-UID/multi/04413/2013).

Received: 12 July 2016 Accepted: 28 October 2016 Published online: 09 November 2016

\section{References}

1. WHO. World Malaria Report 2015. Geneva: World Health Organization; 2015. http://apps.who.int/iris/bitstr eam/10665/200018/1/9789241565158_eng.pdf?ua=1 Accessed 10 Jan 2016.

2. Crompton PD, Moebius J, Portugal S, Waisberg M, Hart G, Garver LS, et al. Malaria immunity in man and mosquito: insights into unsolved mysteries of a deadly infectious disease. Annu Rev Immunol. 2014;32:157-87.

3. Marsh K, Kinyanjui S. Immune effector mechanisms in malaria. Parasite Immunol. 2006;28:51-60.

4. Stephens R, Langhorne J. Priming of CD4+T cells and development of CD4+ T cell memory; lessons for malaria. Parasite Immunol. 2006;28:25-30.

5. Fowkes FJ, McGready R, Cross NJ, Hommel M, Simpson JA, Elliott SR, et al. New insights into acquisition, boosting, and longevity of immunity to malaria in pregnant women. J Infect Dis. 2012;206:1612-21.

6. Faddy HM, Seed CR, Faddy MJ, Flower RL, Harley RJ. Malaria antibody persistence correlates with duration of exposure. Vox Sang. 2013;104:292-8

7. White MT, Griffin JT, Akpogheneta O, Conway DJ, Koram KA, Riley EM, et al. Dynamics of the antibody response to Plasmodium falciparum infection in African children. J Infect Dis. 2014;210:1115-22.

8. Akpogheneta O, Duah NO, Tetteh KK, Dunyo S, Lanar DE, Pinder M, et al. Duration of naturally acquired antibody responses to blood-stage Plasmodium falciparum is age dependent and antigen specific. Infect Immun. 2008;76:1748-55

9. Longley RJ, Reyes-Sandoval A, Montoya-Díaz E, Dunachie S, Kumpitak C, Nguitragool W, et al. Acquisition and longevity of antibodies to Plasmodium vivax preerythrocytic antigens in Western Thailand. Clin Vaccine Immunol. 2016;23:117-24

10. Assennato SM, Berzuini A, Foglieni B, Spreafico M, Allain JP, Prati D. Plasmodium genome in blood donors at risk for malaria after several years of residence in Italy. Transfusion. 2014;54:2419-24.

11. Ashley EA, White NJ. The duration of Plasmodium falciparum infections. Malar J. 2014;13:500

12. Torres KJ, Clark EH, Hernandez JN, Soto-Cornejo KE, Gamboa D, Branch $\mathrm{OH}$. Antibody response dynamics to the Plasmodium falciparum conserved vaccine candidate antigen, merozoite surface protein-1 C-terminal 19 kD (MSP1-19 kD), in Peruvians exposed to hypoendemic malaria transmission. Malar J. 2008;7:173.

13. O'Brien SF, Delage G, Seed CR, Pillonel J, Fabra CC, Davison K, et al. The epidemiology of imported malaria and transfusion policy in 5 nonendemic countries. Transfus Med Rev. 2015;29:162-71.

14. Brouwer EE, van Hellemond JJ, van Genderen PJJ, Slot E, van Lieshout $L$, Visser LG, et al. A case report of transfusion-transmitted Plasmodium malariae from an asymptomatic non-immune traveller. Malar J. 2013;12:439.

15. Anthony CN, Lau Y, Sum J, Fong M, Ariffin H, Zaw W, et al. Malaysian child infected with Plasmodium vivax via blood transfusion: a case report. Malar J. 2013;12:308

16. Prashanth GP, Maralihalli MB, Bagalkot PS, Joshi SN. Intravenous artesunate for transfusion-transmitted Plasmodium vivax malaria in a preterm neonate. Pediatrics. 2012;130:e706-9.
17. Chauhan V, Negi RC, Verma B, Thakur S. Transfusion transmitted malaria in a non-endemic area. J Assoc Physicians India. 2009;57:654-6.

18. Frey-Wettstein M, Maier A, Markwalder K, Münch U. A case of transfusion transmitted malaria in Switzerland. Swiss Med Wkly. 2001;131:320.

19. Kinde-Gazard, Oke J, Gnahoui I, Massougbodji A. The risk of malaria transmission by blood transfusion at Cotonou Benin. Sante. 2000;10:389-92.

20. Ali MSM, Kadaru AA, Mustafa MS. Screening blood donors for malaria parasites in Sudan. Ethiop J Health Dev. 2004;18:70-4.

21. Portugal. Decreto Lei n.0185/2015 de 2 de setembro, 1st serie-N.o 171. Lisbon: Ministério da Saúd; 2015. p. 6805. http://www.hemovigilancia. net/files/Dec_Lei_185_2015_transpoe_diretivas_criterios_suspensao dadores.pdf.

22. European Directorate for the Quality of Medicines and HealthCareCouncil of Europe. Guide to the preparation, use and quality assurance of blood components. Recommendation No. R (95) 15. 18th ed. 2015.

23. WHO. Blood donor counselling: implementation guidelines. Geneva: World Health Organization; 2014. http://www.who.int/bloodsafety/voluntary donation/Blooddonorcounselling.pdf Accessed 9 May 2016.

24. Seed CR, Kitchen A, Davis TME. The current status and potential role of laboratory testing to prevent transfusion-transmitted malaria. Transfus Med Rev. 2005; 19:229-40.

25. Kabiru EW, Kaviti JN. Risk of transfusion malaria in Nairobi. East Afr Med J. 1987;64:825-7.

26. Emeribe AO, Ejezie GC. Haemoparasites of blood donors in Calabar. Trop Geogr Med. 1989;41:61-5.

27. Ibhanesebhor SE, Otobo ES, Ladipo OA. Prevalence of malaria parasitaemia in transfused donor blood in Benin City, Nigeria. Ann Trop Paediatr. 1996;16:93-5.

28. Owusu-Ofori AK, Betson M, Parry CM, Stothard JR, Bates I. Transfusiontransmitted malaria in Ghana. Clin Infect Dis. 2013;56:1735-41.

29. O'Brien SF, Uzicanin S, Choquet K, Yi Q, Fan W, Goldman M. Impact of changes to policy for Mexican risk travel on Canadian blood donor deferrals. Blood Transfus. 2013:11:580-4.

30. Leiby DA, Nguyen ML, Notari EP. Impact of donor deferrals for malaria on blood availability in the United States. Transfusion. 2008;48:2222-8.

31. The American National Red Cross. Donating blood: eligibility criteria: alphabetical. 2015. http://www.redcrossblood.org/donating-blood/eligibilityrequirements/eligibility-criteria-alphabetical-listing. Accessed 9 May 2016.

32. Australian Red Cross Blood Service. Travel_ I have travelled outside Australia. Can I still donate blood?. 2014. http://www.donateblood.com.au/ faq/eligibility/travel-i-have-travelled-outside-australia-can-i-still-donateblood\#malaria. Accessed 9 May 2016.

33. Garraud O, Assal A, Pelletier B, Danic B, Kerleguer A, David B, et al. Overview of revised measures to prevent malaria transmission by blood transfusion in France. Vox Sang. 2008;95:226-31.

34. Kitchen AD, Barbara JAJ, Hewitt PE. Documented cases of post-transfusion malaria occurring in England: a review in relation to current and proposed donor-selection guidelines. Vox Sang. 2005;89:77-80.

35. Grande R, Petrini G, Silvani I, Simoneschi B, Marconi M, Torresani E. Immunological testing for malaria and blood donor deferral: the experience of the Ca' Granda Polyclinic Hospital in Milan. Blood Transfus. 2011:9:162-6.

36. Spain. Royal Decree 1088/2005 of 16 September establishing the minimum technical requisites and conditions for blood donation and for blood transfusion centres and services. Boletín Oficial del Estado. 2005:225:31288-304. https://www.boe.es/buscar/act.php?id=BOE-A2005-15514\&p=20160528\&tn=1. Accessed 22 Apr 2016.

37. Matos A, Sousa A, Araújo F, Maia F, Esteves J, Pinheira M, et al. Manual de Triagem de Dadores de Sangue. 1st ed. Instituto Português do Sangue e da Transplantação; 2014. http://ipst.pt/files/IPST/INFORMACAO_DOCUMENTACAO/ManualTriagemDadoresSangue2014.pdf Accessed 22 Apr 2016.

38. Dias P, Machado R, Ferreira A. Relatório de Imigração, Fronteiras e Asilo 2014. 1st ed. Serviço de Estrangeiros e Fronteiras; 2015. http://sefstat.sef. pt/Docs/Rifa_2014.pdf Accessed 26 May 2016.

39. Kain KC, Lanar DE. Determination of genetic variation within Plasmodium falciparum by using enzymatically amplified DNA from filter paper disks impregnated with whole blood. J Clin Microbiol. 1991;29:1171-4.

40. Snounou G, Viriyakosola S, Zhu XP, Jarra W, Pinheiro L, do Rosario $V E$, et al. High sensitivity of detection of human malaria parasites by the use of nested polymerase chain reaction. Mol Biochem Parasitol. 1993;61:315-20. 
41. Murteira BJF. Análise exploratória de dados-Estatística descritiva. New York: McGraw-Hill; 1993.

42. Siegel S, Castellan NJ. Nonparametric statistics for the behavioral sciences. 2nd ed. New York: McGraw-Hill; 1988.

43. Singh G, Sehgal R. Transfusion-transmitted parasitic infections. Asian J Transfus Sci. 2010;4:73-7.

44. Dustmann C, Frattini T. Imigration: the European experience [Internet]. 2012. p 33. http://www.norface-migration.org/publ_uploads/ NDP_01_12.pdf.

45. Instituto Nacional de Estatística. Revista de Estudos Demográficos. 2014. https://www.ine.pt/xportal/xmain?xpid=INE\&xpgid=ine publicacoes\&PUBLICACOESpub_boui=210786267\&PUBLICACOESmodo $=2$. Accessed 26 May 2016.

46. Askling HH, Bruneel F, Burchard G, Castelli F, Chiodini PL, Grobusch MP, et al. Management of imported malaria in Europe. Malar J. 2012;11:328.

47. Laishram DD, Sutton PL, Nanda N, Sharma VL, Sobti RC, Carlton JM, et al. The complexities of malaria disease manifestations with a focus on asymptomatic malaria. Malar J. 2012;11:29.

48. Baird JK. Age-dependent characteristics of protection v. susceptibility to Plasmodium falciparum. Ann Trop Med Parasitol. 1998:92:367-90.

49. Schellenberg D, Menendez C, Kahigwa E, Aponte J, Vidal J, Tanner M, et al. Intermittent treatment for malaria and anaemia control at time of routine vaccinations in Tanzanian infants: a randomised, placebo-controlled trial. Lancet. 2001;357:1471-7.

50. Alonso PL, Smith T, Schellenberg JR, Masanja H, Mwankusye S, Urassa $H$, et al. Randomised trial of efficacy of SPf66 vaccine against Plasmodium falciparum malaria in children in southern Tanzania. Lancet. 1994;344:1175-81.
51. Mendis C, Del Giudice G, Gamage-Mendis AC, Tougne C, Pessi A, Weerasinghe $S$, et al. Anti-circumsporozoite protein antibodies measure age related exposure to malaria in Kataragama, Sri Lanka. Parasite Immunol. 1992; 14:75-86.

52. World Health Organization. Malaria in children under five. 2016. http:// www.who.int/malaria/areas/high_risk_groups/children/en/ Accessed 10 Jan 2016.

53. Mackintosh CL, Mwangi T, Kinyanjui SM, Mosobo M, Pinches R, Williams $\mathrm{TN}$, et al. Failure to respond to the surface of Plasmodium falciparum infected erythrocytes predicts susceptibility to clinical malaria amongst African children. Int J Parasitol. 2008;38:1445-54.

54. Nguyen ML, GoffT, Gibble J, Steele WR, Leiby DA. Analyzing actual risk in malaria-deferred donors through selective serologic testing. Transfusion. 2013;53:1736-43.

55. Keegan LT, Dushoff J. Population-level effects of clinical immunity to malaria. BMC Infect Dis. 2013;13:428.

56. Druilhe P, Pradier O, Marc JP, Miltgen F, Mazier D, Parent G. Levels of antibodies to Plasmodium falciparum sporozoite surface antigens reflect malaria transmission rates and are persistent in the absence of reinfection. Infect Immun. 1986;53:393-7.

57. Mungai M, Tegtmeier G, Chamberland M, Parise M. Transfusion-transmitted malaria in the United States from 1963 through 1999. N Engl J Med. 2001;344:1973-8.

58. Chauhan V, Negi RC, Verma B, Thakur S. Transfusion-transmitted malaria in a non-endemic area. JAPI. 2009;57:653-4.

59. Candolfi E. Transfusion-transmitted malaria, preventive measures. Transfus Clin Biol. 2005;12:107-13.

\section{Submit your next manuscript to BioMed Central and we will help you at every step:}

- We accept pre-submission inquiries

- Our selector tool helps you to find the most relevant journal

- We provide round the clock customer support

- Convenient online submission

- Thorough peer review

- Inclusion in PubMed and all major indexing services

- Maximum visibility for your research

Submit your manuscript at www.biomedcentral.com/submit
() Biomed Central 